\section{New strategy sought for UK postgraduate medical research}

\section{London}

A SWEEPING review of Britain's largest body for postgraduate medicine is under way, aimed at developing a coordinated policy for research and teaching, moving away from the traditional discipline-based system.

In the face of declining support from central government and increasing reliance on short-term grants from charities and industry, the British Postgraduate Medical Federation is hoping to devise a research infrastructure that will more efficiently harness the federation's scientific expertise and attract longer-term investment from non-government sources.

The federation is a school of the University of London comprising eight postgraduate institutes - Hunterian (the scientific basis of surgery), child health, cancer research, dental surgery, neurology, ophthalmology and psychiatry - and the departments of the postgraduate deans in medicine and dentistry of four public health regions.

Last spring, the federation's new president, Professor Michael Peckham, set up a steering group to consider ways of improving scientific coordination between the institutes, which between them have a total of 92 academic departments, almost 2,000 members of academic staff and 7,500 postgraduate students.

A first draft of the federation's plan was presented to the university authorities last week. The plan shows how government support through the University Grants Committee (UGC) is accounting for an increasingly small proportion of the federation's total income.

In $1980-81$, recurrent grant was $£ 6.6$ million, rising by 16.9 per cent to $£ 7.7$ million by $1986-87$. This contrasts with an increase in income from non-UGC sources over the same period of 139.7 per cent, to $£ 11.98$ million.

Between 1980 and 1987, 132 posts were frozen or lost at the federation, with 152 new posts being gained. However, excluding those at the Institute of Cancer Research, of the posts lost, 97 per cent were UGC-funded, whereas of the new posts, only 15 per cent were UGCsupported. More than 30 per cent of the new posts were supported by charitable bodies.

The plan says that the short-term nature of many of the non-UGC positions "is likely to have serious implications in the long-term, particularly with regard to the career structure of non-clinical scientists" Peckham says that because fundamental scientific research in areas such as molecular and cell biology cut across traditional disciplines, increased cooperation and coordination between the institutes will result in stronger science. Peckham hopes that a more coordinated and

flexible research strategy will also lay the foundations for persuading non-government bodies to invest in longer-term support, with a consequent improvement in the career structures for the researchers. "The reduced attractiveness of medical research as a career option is causing considerable anxiety at the present time", Peckham says.

Simon Hadlington

\title{
AIDS workers going for computer link
}

\section{Washington}

THE World Immunological Network Project Foundation - an organization which promotes hospital videoconferencing - has ambitious plans to link all AIDS researchers worldwide together in computer networks, according to Genevieve Clavreul, the foundation's director.

Clavreul scored her first big success last week by persuading Robert Gallo of the US National Cancer Institute and Luc Montagnier of the Institut Pasteur in France to activate accounts with BITNET - a widely used scientific network in the United States - and the European Academic and Research Network (EARN). Members of Gallo's and Montagnier's laboratories will now be able to communicate electronically, through an interface between the two networks.

By tying together electronically two of the leading centres of AIDS research Clavreul hopes to stimulate increased use of data-sharing and communication networks among the biomedical scientific community. Her ultimate plans are to create a 'subset system' on AIDS research that would allow the exchange of electronic mail, and provide access to AIDSspecific databases and software. Clavreul is working with IBM to encourage biological researchers to tap into electronic mail networks. Most researchers studying AIDS work at institutions already have accounts on major networks such as BITNET and EARN, but biologists have been slower than other scientists to communicate electronically because their work involves less computing.

But despite Clavreul's enthusiasm, the idea of a specialized computer network for the exchange of AIDS information among researchers is not new. The US Presidential Commission on the HIV Epidemic recommended the creation of a computer network for AIDS research in its preliminary report (see Nature 332, 3; 1988). Recently, the American Foundation for AIDS Research convened a meeting of AIDS researchers to discuss whether or not such a network would be useful. The consensus was that communication by facsimile machine and telephone was filling current needs, and that frequent meetings were more beneficial.

Carol Ezzell 